\title{
Integrated vendor-buyer inventory models with inflation and time value of money in controllable lead time
}

\author{
Prashant Jindal ${ }^{\mathrm{a}^{*}}$ and Anjana Solanki ${ }^{\mathrm{b}}$
}

${ }^{a}$ Research scholar, Department of Applied Mathematics, Gautam Buddha University, Greater Noida, Uttar Pradesh, India ${ }^{b}$ Professor, Department of Applied Mathematics, Gautam Buddha University, Greater Noida, Uttar Pradesh, India

\section{H R O N I C L E}

\begin{tabular}{l}
\hline Article history: \\
Received June25, 2015 \\
Received in revised format: \\
June28, 2015 \\
Accepted July31, 2015 \\
Available online \\
August62015 \\
\hline Keywords: \\
Integrated \\
Inflation \\
Time value of money \\
Controllable lead time
\end{tabular}

\section{Introduction}

Conventional inventory management techniques suggest stocking an inventory level for minimizing the system cost. This approach does not handle risk or the time value of money in the recent highly volatile market situations. In most of the research work, the time value of money and inflation were disregarded. If the planning horizon is short, it may be appropriate to ignore the time value of money to simplify the decision process. However, if the planning horizon is long, the time value of money cannot be ignored. To relax the assumption of no inflationary effects on costs, first attempt were of Buzacott (1975) and Misra (1975) who simultaneously developed an EOQ model with a constant inflation rate for all associated costs. After that several researchers extended their approach to various realistic situations by considering the time value of money, different inflation rates for the internal and external costs, finite replenishment rate, shortages, backlogging, etc. Bierman and Thomas (1977) proposed an EOQ model under inflation that also incorporated the discount rate. Misra (1979) extended

\begin{abstract}
In the global critical economic scenario, inflation plays a vital role in deciding optimal pricing of goods in any business entity. This article presents two single-vendor single-buyer integrated supply chain inventory models with inflation and time value of money. Shortage is allowed during the lead time and it is partially backlogged. Lead time is controllable and can be reduced
using crashing cost. In the first model, we consider the demand of lead time follows a normal distribution, and in the second model, it is considered distribution-free. For both cases, our objective is to minimize the integrated system cost by simultaneously optimizing the order quantity, safety factor, lead time and number of lots. The discounted cash flow and classical examples including the sensitivity analysis of system parameters is provided to validate the results of the supply chain models.
\end{abstract}

E-mail address: pras.jindal@gmail.com(P. Jindal) 
the EOQ model with different inflation rates for various associated costs. Studying inventory models while considering time and value, Moon and Yun (1993) worked on the discounted cash flow approach to fully distinguish the time value of money and formulated a finite planning horizon EOQ model in which the planning horizon is a random variable. Sarker and Pan (1994) surveyed the effects of inflation and the time value of money on order quantity with finite replenishment rate. Ray and Chaudhuri (1997) presented an EOQ model under inflation and time discounting allowing shortages. Wee and Law (1999) employed the concept of inflation and time value of money into the model with price dependent demand and allowable shortage. Horowitz (2000) discussed a simple EOQ model with a normal distribution for the inflation rate. Further, Wee and Law (2001) presented a heuristic approach to derive the near optimal replenishment and pricing policy that tries to maximize the total net present-value profit. They applied the discounted cash flows (DCF) approach for problem analysis. Balkhi (2004) considered a production lot size inventory model with deterioration and imperfect products, taking into account inflation and the time value of money. Then, Yang et al. (2005) provided a mixed inventory model, in which the distribution of lead time demand is normal, to consider the time value. Recently,

A large number of inventory models dealing with inflation and time value of money are available in the literature. However, the literature is inadequate as far as the supply chain model is concerned. All the above works have been done on inventory modeling is only for a single echelon either vendor or buyer. Lo et al. (2007) developed an integrated production-inventory model under the assumptions of varying deterioration rate, partial backordering and inflation. Chern et al. (2008) proposed partial backlogging inventory lot-size models for deteriorating items with fluctuating demand under inflation. Uthayakumar and Geetha (2009) proposed an optimal replenishment policy by considering stock dependent consumption rate for non-instantaneous deteriorating items with money inflation and partially backlogging. Shah and Shukla (2010) proposed a study, for demand declining market, without shortages under the effect of inflation. Recently, Mirzazadeh (2011) proposed a detailed comparison of the average annual cost and the discounted cost models under stochastic inflationary conditions. Further, Mirzazadeh (2013) developed an inventory model under stochastic inflationary conditions with variable probability density functions where demand rate is assumed to be dependent on the inflation rates. Recently Jindal \& Solanki (2014) discussed integrated inventory model with backorder price discount and controllable lead time.

Usually, the effect of inflation and time value of money is not considered in supply chain inventory models, although inflation and time value of money would influence the cost and price components to a significant degree. The effect of inflation and time value of money for determining the integrated supply chain cost of inventory modeling cannot be ignored. The effect of inflation and time value of money should be considered in developing the proper mathematical formulation of the supply chain. Controlling the lead time is an effective way to achieve balance between the two factors of time and costs. In the past, lead time crashing cost, inflation and the time value of money have received attention separately, but they considered together simultaneously very rarely. The purpose of this paper is to develop an inventory model with a lead time crashing cost with taking into account time value of money and inflation. First we consider lead time demand follows normal distribution then, we relax the assumption on the distributional form of lead time demand and merely assume that the first and second moments are known and finite. For this case, we solve the problem by applying the minimax distribution-free approach

\section{Notations and assumptions}

To develop the proposed models, we adopt the following notations and assumptions.

\subsection{Notations}

$D \quad$ Average demand per year of the buyer

$P \quad$ Production rate on the vendor $P>D$

$Q \quad$ Order quantity of the buyer (decision variable) 
A Buyer's ordering cost per order

$S \quad$ Vendor's set-up cost per set-up

$h_{b} \quad$ Buyer's holding cost per unit per year

$h_{v} \quad$ Vendor's holding cost per unit per year

$\theta \quad$ Interest rate per year that is compounded continuously

$\beta \quad$ Fraction of the demand during the stockout period that will be backordered, $\beta \in[0,1]$

$\pi \quad$ Buyer's penalty cost per unit short

$\pi_{o} \quad$ Buyer's marginal profit per unit, i.e., cost of lost demand per unit

$C(L) \quad$ Lead time crashing cost

$R \quad$ Reorder point of the buyer

$K \quad$ Safety factor (decision variable)

$L \quad$ Length of lead time for the buyer (decision variable)

$M \quad$ An integer representing the number of lots in which the items are delivered from the vendor to the buyer (decision variable)

$X \quad$ Lead time demand with finite mean DL and standard deviation $\sigma \sqrt{L}>0$

$E($. ) Mathematical expectation

$x^{+} \quad$ Maximum value of $\mathrm{x}$ and 0 , i.e., $\mathrm{x}^{+}=\operatorname{Max}\{\mathrm{x}, 0\}$.

\subsection{Assumptions}

1. There is single vendor and single buyer for a single product.

2. Inventory is continuously reviewed and replenishments are made whenever the inventory level falls to the reorder point $r$.

3. The reorder point $\mathrm{r}=$ expected demand during lead time + safety stock (SS) and $\mathrm{SS}=\mathrm{k} \times$ (standard deviation of lead time demand), that is, $r=D L+k \sigma \sqrt{L}$

4. The buyer orders a lot of size $\mathrm{Q}$ and the vendor produces $\mathrm{mQ}$ units with a finite production rate $\mathrm{P}$ at one set-up but ship in quantity $\mathrm{Q}$ to the buyer over $\mathrm{m}$ times.

5. The lead time $\mathrm{L}$ consists of $\mathrm{n}$ mutually independent components. The $\mathrm{i}^{\text {th }}$ component has a minimum duration $a_{i}$,normal duration $b_{i}$, and crashing cost per unit time $c_{i}$,For convenience, we rearrange $c_{i}$ such that $c_{1}<c_{2}<\cdots<c_{n}$. The components of lead time are crashed one at a time starting from the first component because it has the minimum unit crashing cost, and then the second component, and so on.

6. Let $\mathrm{L}_{\mathrm{o}}=\sum_{\mathrm{j}=1}^{\mathrm{n}} \mathrm{b}_{\mathrm{j}}$ and $\mathrm{L}_{\mathrm{i}}$ be the length of lead time with components $1,2, \ldots$, i crashed to their minimum duration, then $L_{i}$ can be expressed as $L_{i}=\sum_{j=1}^{n} b_{j}-\sum_{j=1}^{i}\left(b_{j}-a_{j}\right), i=1,2, \ldots, n$; and the lead time crashing cost $C(L)$ per cycle for a given $L \in\left[L_{i}, L_{i-1}\right]$, is given by $C(L)=$ $c_{i}\left(L_{i-1}-L_{i}\right)+\sum_{j=1}^{i-1} c_{j}\left(b_{j}-a_{j}\right)$. In addition, the length of lead time is equal for all shipping cycles, and the lead time crashing cost occurs in each cycle.

\section{The model}

In this paper, two integrated single vendor and single buyer inventory models with controllable lead time under inflation and time vale of money are discussed. We simultaneously optimize the order quantity, safety factor, lead time and the number of lots delivered from vendor to buyer with the objective of minimizing the total supply chain integrated cost. Inventory is continuously reviewed; we assume that the integrated production inventory model allows shortages with partial backorder. Replenishments are made whenever the inventory level falls to the reorder point $r$. The lead time demand $\mathrm{X}$ has a p.d.f. $\mathrm{f}(\mathrm{x})$ with finite mean DL and standard deviation $\sigma \sqrt{L}>0$.

\subsection{Buyer's cost}

The expected shortage at the end of each cycle is given by $E(X-r)^{+}$. Thus the expected number of backorders and loss in sales per cycle is $\beta E(X-r)^{+}$and $(1-\beta) E(X-r)^{+}$respectively. 
For each cycle, when shortage is occurred, the fixed shortage cost is $\pi E(X-r)^{+}$and the loss profit is $\pi_{o}(1-\beta) E(X-r)^{+}$. Hence, the stockout cost per cycle is $\left[\pi+\pi_{o}(1-\beta)\right] E(X-r)^{+}$. The expected net inventory level just before the order arrives is $k \sigma \sqrt{L}+(1-\beta) E(X-r)^{+}$and the expected net inventory at the beginning of the cycle is $Q+k \sigma \sqrt{L}+(1-\beta) E(X-r)^{+}$. Therefore, the expected average inventory level is $Q+k \sigma \sqrt{L}+(1-\beta) E(X-r)^{+}-D t$ for $t \in\left[0, \frac{Q}{D}\right]$. Hence, the inventory holding cost for the first cycle equals $\int_{t=0}^{\frac{Q}{D}}\left[Q+k \sigma \sqrt{L}+(1-\beta) E(X-r)^{+}-D t\right] h_{b} e^{-\theta t} d t$

$$
=\left[k \sigma \sqrt{L}+(1-\beta) E(X-r)^{+}\right] \frac{h_{b}}{\theta}\left(1-e^{-\frac{\theta Q}{D}}\right)+\frac{D h_{b}}{\theta^{2}}\left(\frac{\theta Q}{D}+e^{-\frac{\theta Q}{D}}-1\right)
$$

Applying the discounted cash flow approach of Moon and Yun (1993) the total cost for the buyer at the first cycle is the sum of the ordering cost, holding cost, stockout cost, and lead time crashing cost, is expressed by

$$
\begin{gathered}
T C_{b}(Q, k, L)=A+\left[k \sigma \sqrt{L}+(1-\beta) E(X-r)^{+}\right] \frac{h_{b}}{\theta}\left(1-e^{-\frac{\theta Q}{D}}\right)+\frac{D h_{b}}{\theta^{2}}\left(\frac{\theta Q}{D}+e^{-\frac{\theta Q}{D}}-1\right) \\
+\left[\pi+\pi_{o}(1-\beta)\right] E(X-r)^{+}+C(L)
\end{gathered}
$$

Referring to Yang et al. (2005), we get the present value of the expected total cost for the buyer over infinite time horizon

$$
\begin{aligned}
\operatorname{PTC}_{b}(Q, k, L)= & \frac{1}{\left(1-e^{-\frac{\theta Q}{D}}\right)} T C_{b}(Q, k, L) \\
& =\frac{A+C(L)+\left[\pi+\pi_{o}(1-\beta)\right] E(X-r)^{+}}{\left(1-e^{-\frac{\theta Q}{D}}\right)}+\frac{Q h_{b}}{\theta\left(1-e^{-\frac{\theta Q}{D}}\right)}+\left[k \sigma \sqrt{L}+(1-\beta) E(X-r)^{+}\right] \frac{h_{b}}{\theta}-\frac{D h_{b}}{\theta^{2}}
\end{aligned}
$$

\subsection{Vendor's cost}

For each production period, when first Q units have been produced, the vendor delivers them to the buyer, after that the vendor will make the deliveries on average every $\frac{Q}{D}$ units of time until the inventory level vanishes. Also the vendor produces $m Q$ quantity in a lot. Since the cycle length for the vendor is $\frac{m Q}{D}$, hence the vendor's average inventory can be calculated as follows

$\left[m Q\left\{\frac{Q}{P}+(m-1) \frac{Q}{D}\right\}-\frac{m^{2} Q^{2}}{2 P}-\frac{Q^{2}}{D}\{1+2+\cdots+(m-1)\}\right] \frac{D}{m Q}=\frac{Q}{2}\left[(m-1)+(2-m) \frac{D}{P}\right]$

for $t \in\left[0, \frac{m Q}{D}\right]$. Therefore, the holding cost for the vendor at the first cycle equals

$$
\int_{t=0}^{\frac{m Q}{D}} \frac{Q h_{v}}{2}\left[(m-1)+(2-m) \frac{D}{P}\right] e^{-\theta t} d t=\frac{Q h_{v}}{2 \theta}\left[(m-1)+(2-m) \frac{D}{P}\right]\left(1-e^{-\frac{m \theta Q}{D}}\right)
$$

Thus the total cost of the vendor at first cycle, which is composite of set-up cost and holding cost is expressed by

$$
T C_{v}(Q, m)=S+\frac{Q h_{v}}{2 \theta}\left[(m-1)+(2-m) \frac{D}{P}\right]\left(1-e^{-\frac{m \theta Q}{D}}\right)
$$

Accordingly, the present value of the total cost of the vendor over infinite time horizon is

$$
P T C_{v}(Q, m)=\frac{1}{\left(1-e^{-\frac{m \theta Q}{D}}\right)} T C_{v}(Q, m)=\frac{S}{\left(1-e^{-\frac{m \theta Q}{D}}\right)}+\frac{Q h_{v}}{2 \theta}\left[(m-1)+(2-m) \frac{D}{P}\right]
$$

Considering vendor and buyer cooperation to each other, the integrated supply chain total cost at the first cycle is given by

$$
P T C_{s c}(Q, k, L, m)=P T C_{b}(Q, k, L)+P T C_{v}(Q, m)
$$




$$
\begin{gathered}
=\frac{A+C(L)+\left[\pi+\pi_{o}(1-\beta)\right] E(X-r)^{+}}{\left(1-e^{-\frac{\theta Q}{D}}\right)}+\frac{Q h_{b}}{\theta\left(1-e^{-\frac{\theta Q}{D}}\right)}+\left[k \sigma \sqrt{L}+(1-\beta) E(X-r)^{+}\right] \frac{h_{b}}{\theta}-\frac{D h_{b}}{\theta^{2}}+\frac{S}{\left(1-e^{-\frac{m \theta Q}{D}}\right)} \\
+\frac{Q h_{v}}{2 \theta}\left[(m-1)+(2-m) \frac{D}{P}\right]
\end{gathered}
$$

\section{The Optimal Solution}

Two cases are considered for stochastic lead time demand, one when the lead time demand follows a normal distribution and other when lead time demand is distribution free.

\section{Case I -The Lead Time Demand Follows a Normal Distribution}

In this case, we assume that the lead-time demand $\mathrm{X}$ is normally distributed with finite mean DL, standard deviation $\sigma \sqrt{L}$, and reorder point $r=D L+k \sigma \sqrt{L}$. Therefore the expected shortages quantity at the end of the cycle is given by

$E(X-r)^{+}=\int_{r}^{\infty}(x-r) d f(x)=\sigma \sqrt{L} \psi(k)>0$, where $\psi(k)=\phi(k)-k[1-\Phi(k)]>0$

where $\phi$ and $\Phi$ denote the standard normal probability density function and distribution function respectively. Thus, the joint total expected cost given by Eq. (3), transforms to

$$
P T C_{s c}(Q, k, L, m)=\frac{A+C(L)+\bar{\pi} \sigma \sqrt{L} \psi(k)}{\left(1-e^{-\frac{\theta Q}{D}}\right)}+\frac{Q h_{b}}{\theta\left(1-e^{-\frac{\theta Q}{D}}\right)}+\frac{s}{\left(1-e^{-\frac{m \theta Q}{D}}\right)}+\frac{Q}{2 \theta} H(m)+[k+(1-
$$

$\beta) \psi(k)] \frac{\sigma \sqrt{L} h_{b}}{\theta}-\frac{D h_{b}}{\theta^{2}}$

To simplify notations, we let $\bar{\pi}=\left[\pi+\pi_{o}(1-\beta)\right]$ and $H(m)=h_{v}\left[(m-1)+(2-m) \frac{D}{P}\right]$

Taking first and second order partial derivatives of $P T C_{s c}(Q, k, L, m)$ for fixed $\mathrm{Q}, \mathrm{k}$ and $\mathrm{m}$, with respect to L, we have

$\frac{\partial \mathrm{PTC}_{\mathrm{Sc}}(\mathrm{Q}, \mathrm{k}, \mathrm{L}, \mathrm{m})}{\partial L}=\frac{\bar{\pi} \sigma L^{-\frac{1}{2}} \psi(k)}{2\left(1-e^{-\frac{\theta Q}{D}}\right)}-\frac{\mathrm{C}_{\mathrm{i}}}{\left(1-e^{-\frac{\theta Q}{D}}\right)}+[\mathrm{k}+(1-\beta) \psi(\mathrm{k})] \frac{\sigma \mathrm{h}_{\mathrm{b}} L^{-\frac{1}{2}}}{2 \theta}$

$\frac{\partial^{2} \mathrm{PTC}_{\mathrm{sc}}(\mathrm{Q}, \mathrm{k}, \mathrm{L}, \mathrm{m})}{\partial L^{2}}=-\frac{\bar{\pi} \sigma L^{-\frac{3}{2}} \psi(k)}{4\left(1-e^{-\frac{\theta Q}{D}}\right)}-[\mathrm{k}+(1-\beta) \psi(\mathrm{k})] \frac{\sigma \mathrm{h}_{\mathrm{b}} L^{-\frac{3}{2}}}{4 \theta}<0$

Therefore, for fixed $(\mathrm{Q}, \mathrm{k}, \mathrm{m}), \mathrm{PTC}_{\mathrm{sc}}(\mathrm{Q}, \mathrm{k}, \mathrm{L}, \mathrm{m})$ is a concave function in $\left[\mathrm{L}_{\mathrm{i}}, \mathrm{L}_{\mathrm{i}-1}\right]$. Hence, for fixed $(\mathrm{Q}$, $\mathrm{k}, \mathrm{m}$ ), the minimum integrated total supply chain cost will occur at the end points of the interval $\left[\mathrm{L}_{\mathrm{i}}, \mathrm{L}_{\mathrm{i}-1}\right]$. Now for fixed integer $\mathrm{m}$, let us take the partial derivatives of $\mathrm{PTC}_{\mathrm{sc}}(\mathrm{Q}, \mathrm{k}, \mathrm{L}, \mathrm{m})$ with respect to $\mathrm{Q}$ and $\mathrm{k}$, we obtain

$$
\begin{gathered}
\frac{\partial \mathrm{PTC}_{\mathrm{sc}}(\mathrm{Q}, \mathrm{k}, \mathrm{L}, \mathrm{m})}{\partial Q}=-\left\{A+C(L)+\bar{\pi} \sigma \sqrt{L} \psi(k)+\frac{Q h_{b}}{\theta}\right\} \frac{\theta e^{-\frac{\theta Q}{D}}}{D\left(1-e^{-\frac{\theta Q}{D}}\right)^{2}}-\frac{S m \theta e^{-\frac{m \theta Q}{D}}}{D\left(1-e^{-\frac{m \theta Q}{D}}\right)^{2}}+\frac{h_{b}}{\theta\left(1-e^{-\frac{\theta Q}{D}}\right)}+\frac{H(m)}{2 \theta} \\
\frac{\partial \mathrm{PTC}_{\mathrm{sc}}(\mathrm{Q}, \mathrm{k}, \mathrm{L}, \mathrm{m})}{\partial k}=\left\{\frac{\bar{\pi} \sigma \sqrt{L}}{\left(1-e^{-\frac{\theta Q}{D}}\right)}+(1-\beta) \frac{\sigma \sqrt{L} h_{b}}{\theta}\right\}[\Phi(k)-1]+\frac{\sigma \sqrt{L} h_{b}}{\theta}
\end{gathered}
$$

However $P_{T C}(Q, k, L, m)$ is convex for $Q$ and $k$, for fixed $m$ and $L \in\left[L_{i}, L_{i-1}\right]$ (for proof, see the appendix A). We can obtain the optimal values of $Q$ and k, by setting Eq. (5) and Eq. (6) equal to zero, which gives 


$$
\begin{aligned}
& \mathrm{Q}=\left[\frac{\mathrm{D}}{2 \theta} H(m)-\frac{S m \theta e^{-\frac{m \theta Q}{D}}}{\left(1-e^{-\frac{m \theta Q}{D}}\right)^{2}}\right] \frac{\left(e^{\frac{\theta Q}{D}}+e^{-\frac{\theta Q}{D}}-2\right)}{h_{b}}-\{A+C(L)+\bar{\pi} \sigma \sqrt{L} \psi(k)\} \frac{\theta}{h_{b}}+\frac{\mathrm{D}}{\theta}\left(e^{\frac{\theta Q}{D}}-1\right) \\
& 1-\Phi(k)=h_{b} /\left\{\frac{\theta \bar{\pi}}{\left(1-e^{-\frac{\theta Q}{D}}\right)}+(1-\beta) h_{b}\right\}
\end{aligned}
$$

\section{Case II -The Lead Time Demand is Distribution Free}

Practically it is seen that, the information about lead time demand probability distribution is limited. Hence here in this case, we assume, given finite first and second moments. Consequently mean and variance are also finite and known; i.e., the density function $\mathrm{f}(\mathrm{x})$ of lead time demand $\mathrm{X}$ belongs to the class $\mathfrak{R o f}$ density functions with finite mean $\mathrm{DL}$ and variance $\sigma^{2} L$. Since the probability distribution of $\mathrm{X}$ is unknown, the exact value of the expected demand shortages (or expected shortages quantity) $E(X-r)^{+}$at the end of the shipping cycle cannot be found. Therefore, we use the minimax distribution free procedure to solve this problem. The minimax distribution free approach involves finding the most unfavorable density function $\mathrm{f}(\mathrm{x})$ in $\Re$ for each $(Q, k, L, m)$ and then minimizes the joint total expected cost per unit time over $(Q, k, L, m)$. That is, our problem is to solve

$$
\min _{(\mathrm{Q}, \mathrm{k}, \mathrm{L}, \mathrm{m})} \max _{f(x) \in \mathfrak{R}} \mathrm{PTC}_{\mathrm{sc}}(\mathrm{Q}, \mathrm{k}, \mathrm{L}, \mathrm{m})
$$

To solve our problem, we apply following proposition, asserted by Gallego and Moon (1993)

\section{Proposition 1.}

For any $f(x) \in \mathfrak{R}, E(X-r)^{+} \leq \frac{1}{2}\left[\sqrt{\sigma^{2} L+(r-D L)^{2}}-(r-D L)\right]$

Moreover, the upper bound of the above inequality is tight.

Since the above inequality always holds for any lead time demand probability distribution. Then using the model, explained by Eq. (3) and Eq. (9), and considering the safety factor $\mathrm{k}$ as a decision variable instead of $r$, the problem (4) is reduced to minimize

$$
\begin{aligned}
& \operatorname{PTC}_{\mathrm{sc}}^{\mathrm{M}}(\mathrm{Q}, \mathrm{k}, \mathrm{L}, \mathrm{m})=\frac{A+C(L)+\frac{Q}{\theta} h_{b}+\frac{\bar{\pi}}{2} \sigma \sqrt{L}\left(\sqrt{1+k^{2}}-k\right)}{\left(1-e^{-\frac{\theta Q}{D}}\right)}+\frac{S}{\left(1-e^{-\frac{m \theta Q}{D}}\right)}+\frac{Q}{2 \theta} H(m)+\left[k+\frac{1}{2}(1-\right. \\
& \left.\beta)\left(\sqrt{1+k^{2}}-k\right)\right] \frac{\sigma \sqrt{L} h_{b}}{\theta}-\frac{D h_{b}}{\theta^{2}}
\end{aligned}
$$

Taking first and second order partial derivatives of $\operatorname{PTC}_{\mathrm{sc}}^{\mathrm{M}}(\mathrm{Q}, \mathrm{k}, \mathrm{L}, \mathrm{m})$ for fixed $\mathrm{Q}, \mathrm{k}$ and $\mathrm{m}$, with respect to L, we have

$$
\begin{aligned}
& \frac{\partial \operatorname{PTC}_{\mathrm{SC}}^{\mathrm{M}}(\mathrm{Q}, \mathrm{k}, \mathrm{L}, \mathrm{m})}{\partial L}=\frac{\bar{\pi} \sigma L^{-\frac{1}{2}}\left(\sqrt{1+k^{2}}-k\right)}{4\left(1-e^{-\frac{\theta Q}{D}}\right)}+\left[k+\frac{1}{2}(1-\beta)\left(\sqrt{1+k^{2}}-k\right)\right] \frac{\sigma \mathrm{h}_{\mathrm{b}} L^{-\frac{1}{2}}}{2 \theta}-\frac{\mathrm{C}_{\mathrm{i}}}{\left(1-e^{-\frac{\theta Q}{D}}\right)} \\
& \frac{\partial^{2} \operatorname{PTC}_{\mathrm{Sc}}^{\mathrm{M}}(\mathrm{Q}, \mathrm{k}, \mathrm{L}, \mathrm{m})}{\partial L^{2}}=-\frac{\bar{\pi} \sigma L^{-\frac{3}{2}}\left(\sqrt{1+k^{2}}-k\right)}{8\left(1-e^{-\frac{\theta Q}{D}}\right)}-\left[k+\frac{1}{2}(1-\beta)\left(\sqrt{1+k^{2}}-k\right)\right] \frac{\sigma \mathrm{h}_{\mathrm{b}} L^{-\frac{3}{2}}}{4 \theta}<0
\end{aligned}
$$

Therefore, for fixed $(\mathrm{Q}, \mathrm{k}, \mathrm{m}), \mathrm{PTC}_{\mathrm{sc}}^{\mathrm{M}}(\mathrm{Q}, \mathrm{k}, \mathrm{L}, \mathrm{m})$ is a concave function in $\left[\mathrm{L}_{\mathrm{i}}, \mathrm{L}_{\mathrm{i}-1}\right]$. Hence, for fixed $(\mathrm{Q}, \mathrm{k}, \mathrm{m})$, the minimum integrated total supply chain cost will occur at the end points of the interval $\left[\mathrm{L}_{\mathrm{i}}, \mathrm{L}_{\mathrm{i}-1}\right]$. In order to find the optimal values of decision variables, we relax the integer constraint on $\mathrm{m}$, let us take the partial derivatives of $\operatorname{PTC}_{\mathrm{sc}}^{\mathrm{M}}(\mathrm{Q}, \mathrm{k}, \mathrm{L}, \mathrm{m})$ with respect to $\mathrm{Q}$ and $\mathrm{k}$, we obtain 


$$
\begin{aligned}
& \frac{\partial \operatorname{PTC}_{\mathrm{sc}}^{\mathrm{M}}(\mathrm{Q}, \mathrm{k}, \mathrm{L}, \mathrm{m})}{\partial Q}=-\left\{A+C(L)+\frac{\bar{\pi}}{2} \sigma \sqrt{L}\left(\sqrt{1+k^{2}}-k\right)+\frac{Q h_{b}}{\theta}\right\} \frac{\theta e^{-\frac{\theta Q}{D}}}{D\left(1-e^{-\frac{\theta Q}{D}}\right)^{2}}-\frac{S m \theta e^{-\frac{m \theta Q}{D}}}{D\left(1-e^{-\frac{m \theta Q}{D}}\right)^{2}} \\
&+\frac{h_{b}}{\theta\left(1-e^{-\frac{\theta Q}{D}}\right)}+\frac{H(m)}{2 \theta} \\
& \frac{\partial \operatorname{PTC}_{\mathrm{SC}}^{\mathrm{M}}(\mathrm{Q}, \mathrm{k}, \mathrm{L}, \mathrm{m})}{\partial k}=\left\{\frac{\bar{\pi} \sigma \sqrt{L}}{2\left(1-e^{-\frac{\theta Q}{D}}\right)}+(1-\beta) \frac{\sigma \sqrt{L} h_{b}}{2 \theta}\right\}\left[\frac{k}{\sqrt{1+k^{2}}}-1\right]+\frac{\sigma \sqrt{L} h_{b}}{\theta}
\end{aligned}
$$

However $\operatorname{PTC}_{\mathrm{sc}}^{\mathrm{M}}(\mathrm{Q}, \mathrm{k}, \mathrm{L}, \mathrm{m})$ is convex for $\mathrm{Q}$ and $\mathrm{k}$, for fixed $\mathrm{m}$ and $\mathrm{L} \in\left[\mathrm{L}_{\mathrm{i}}, \mathrm{L}_{\mathrm{i}-1}\right]$ (for proof, see the appendix B). We can obtain the optimal values of $Q$ and k, by setting Eq. (11) and Eq. (12) equal to zero, which gives

$$
\begin{aligned}
& \mathrm{Q}=\left[\frac{\mathrm{D}}{2 \theta} H(m)-\frac{S m \theta e^{-\frac{m \theta Q}{D}}}{\left(1-e^{-\frac{m \theta Q}{D}}\right)^{2}}\right] \frac{\left(e^{\frac{\theta Q}{D}}+e^{-\frac{\theta Q}{D}}-2\right)}{h_{b}}-\left\{A+C(L)+\frac{\bar{\pi}}{2} \sigma \sqrt{L}\left(\sqrt{1+k^{2}}-k\right)\right\} \frac{\theta}{h_{b}}+\frac{\mathrm{D}}{\theta}\left(e^{\frac{\theta Q}{D}}-1\right) \\
& 1-\frac{k}{\sqrt{1+k^{2}}}=2 h_{b} /\left\{\frac{\theta \bar{\pi}}{\left(1-e^{-\frac{\theta Q}{D}}\right)}+(1-\beta) h_{b}\right\}
\end{aligned}
$$

\section{Numerical Examples}

\section{Example 1.}

In order to illustrate the above proposed models, let us consider an inventory system with the following data: $\mathrm{D}=600$ units/year, $\mathrm{P}=2000$ units/year, $\mathrm{A}=\$ 200$ /order, $\mathrm{S}=\$ 1000 /$ set-up, $\pi=\$ 50 /$ unit, $\pi_{o}=150 /$ unit, $h_{b}=\$ 20 /$ unit/year, $h_{v}=\$ 15 /$ unit/year, $\sigma=7$ units/week and $\theta=0.1$. The lead time has three components with data shown in Table 1. We assume here that the lead time demand follows a normal distribution. The solution procedure for different values of $\beta=0,0.25,0.50,0.75,1$ is provided in Table 2 and summarizes the results in Table 3. Where $Q=100, k=3$ are taken as initial guess.

\section{Example 2.}

The data is the same as in Example 1 except the probability distribution of the lead time demand is unknown. We obtain the related results which are shown in Table 4 and summarizes the results in Table 5.

\section{Table 1}

Lead time data

\begin{tabular}{cccc}
\hline $\begin{array}{c}\text { Lead time } \\
\text { component, } \mathrm{i}\end{array}$ & $\begin{array}{c}\text { Normal duration } \\
\mathrm{b}_{\mathrm{i}} \text { (days) }\end{array}$ & $\begin{array}{c}\text { Minimum duration } \\
\mathrm{a}_{\mathrm{i}} \text { (days) }\end{array}$ & $\begin{array}{c}\text { Unit crashing cost } \\
\mathrm{C}_{\mathrm{i}}(\$ / \text { day })\end{array}$ \\
\hline 1 & 20 & 6 & 0.4 \\
2 & 20 & 6 & 1.2 \\
3 & 16 & 9 & 5.0 \\
\hline
\end{tabular}


Table 2

Solution procedures for numerical example 1

\begin{tabular}{|c|c|c|c|c|c|c|}
\hline$\beta$ & $\mathrm{m}$ & $\mathrm{L}$ & $\mathrm{C}(\mathrm{L})$ & $\mathrm{Q}$ & $\mathrm{k}$ & $P T C_{S C}(Q, k, L, m)$ \\
\hline \multirow[t]{4}{*}{0} & 1 & 4 & 22.4 & 94.9107 & 2.158 & 96609 \\
\hline & 2 & 4 & 22.4 & 97.8484 & 2.147 & 69097 \\
\hline & 3 & 4 & 22.4 & 99.1193 & 2.143 & 63815 \\
\hline & 4 & 4 & 22.4 & 99.9737 & 2.137 & 64051 \\
\hline \multirow[t]{4}{*}{0.25} & 1 & 4 & 22.4 & 94.9112 & 2.075 & 96350 \\
\hline & 2 & 4 & 22.4 & 97.8489 & 2.062 & 68856 \\
\hline & 3 & 4 & 22.4 & 99.1199 & 2.056 & 63627 \\
\hline & 4 & 4 & 22.4 & 99.9742 & 2.054 & 63754 \\
\hline \multirow[t]{4}{*}{0.50} & 1 & 4 & 22.4 & 94.9117 & 1.963 & 96100 \\
\hline & 2 & 4 & 22.4 & 97.8494 & 1.950 & 68592 \\
\hline & 3 & 4 & 22.4 & 99.1204 & 1.945 & 63347 \\
\hline & 4 & 4 & 22.4 & 99.9747 & 1.942 & 63492 \\
\hline \multirow[t]{4}{*}{0.75} & 1 & 4 & 22.4 & 94.9123 & 1.804 & 95714 \\
\hline & 2 & 4 & 22.4 & 97.8499 & 1.791 & 68191 \\
\hline & 3 & 4 & 22.4 & 99.1209 & 1.785 & 62953 \\
\hline & 4 & 4 & 22.4 & 99.9752 & 1.782 & 63088 \\
\hline \multirow[t]{4}{*}{1} & 1 & 4 & 22.4 & 94.9128 & 1.532 & 95044 \\
\hline & 2 & 4 & 22.4 & 97.8505 & 1.517 & 67522 \\
\hline & 3 & 4 & 22.4 & 99.1214 & 1.510 & 62284 \\
\hline & 4 & 4 & 22.4 & 99.9758 & 1.506 & 62424 \\
\hline
\end{tabular}

Table 3

Summary of the optimal solution for numerical example 1

\begin{tabular}{lllllll}
\hline$\beta$ & $\mathrm{L}$ & $\mathrm{C}(\mathrm{L})$ & $\mathrm{m}$ & $\mathrm{Q}$ & $\mathrm{k}$ & $P T C_{s c}(Q, k, L, m)$ \\
\hline 0 & 4 & 22.4 & 3 & 99.1193 & 2.143 & 63815 \\
0.25 & 4 & 22.4 & 3 & 99.1199 & 2.056 & 63627 \\
0.50 & 4 & 22.4 & 3 & 99.1204 & 1.945 & 63347 \\
0.75 & 4 & 22.4 & 3 & 99.1209 & 1.785 & 62953 \\
1 & 4 & 22.4 & 3 & 99.1214 & 1.510 & 62284 \\
\hline
\end{tabular}

Table 4

Solution procedures for numerical example 2

\begin{tabular}{|c|c|c|c|c|c|c|}
\hline$\beta$ & $\mathrm{m}$ & $\mathrm{L}$ & $\mathrm{C}(\mathrm{L})$ & $\mathrm{Q}$ & $\mathrm{k}$ & $\mathrm{PTC}_{\mathrm{sc}}^{\mathrm{M}}(\mathrm{Q}, \mathrm{k}, \mathrm{L}, \mathrm{m})$ \\
\hline \multirow[t]{5}{*}{0} & 1 & 3 & 57.4 & 93.7547 & 3.9533 & 112080 \\
\hline & 2 & 3 & 57.4 & 96.6924 & 3.8913 & 83756 \\
\hline & 3 & 3 & 57.4 & 97.9634 & 3.8654 & 78182 \\
\hline & 4 & 3 & 57.4 & 98.8177 & 3.8482 & 78112 \\
\hline & 5 & 3 & 57.4 & 99.5053 & 3.8346 & 80237 \\
\hline \multirow[t]{5}{*}{0.25} & 1 & 3 & 57.4 & 93.9392 & 3.5381 & 109970 \\
\hline & 2 & 3 & 57.4 & 96.8769 & 3.4821 & 81749 \\
\hline & 3 & 3 & 57.4 & 98.1478 & 3.4586 & 76218 \\
\hline & 4 & 3 & 57.4 & 99.0021 & 3.4431 & 76176 \\
\hline & 5 & 3 & 57.4 & 99.6898 & 3.4307 & 78324 \\
\hline \multirow[t]{5}{*}{0.50} & 1 & 3 & 57.4 & 94.1236 & 3.0692 & 107610 \\
\hline & 2 & 3 & 57.4 & 97.0613 & 3.0197 & 79499 \\
\hline & 3 & 3 & 57.4 & 98.3323 & 2.9990 & 74014 \\
\hline & 4 & 3 & 57.4 & 99.1866 & 2.9853 & 74001 \\
\hline & 5 & 3 & 57.4 & 99.8742 & 2.9744 & 76172 \\
\hline \multirow[t]{4}{*}{0.75} & 1 & 4 & 22.4 & 94.4165 & 2.5154 & 104510 \\
\hline & 2 & 4 & 22.4 & 97.3542 & 2.4734 & 76595 \\
\hline & 3 & 4 & 22.4 & 98.6252 & 2.4558 & 71189 \\
\hline & 4 & 4 & 22.4 & 99.4795 & 2.4441 & 71229 \\
\hline \multirow[t]{4}{*}{1} & 1 & 4 & 22.4 & 94.6295 & 1.8058 & 100570 \\
\hline & 2 & 4 & 22.4 & 97.5672 & 1.7726 & 72802 \\
\hline & 3 & 4 & 22.4 & 98.8382 & 1.7587 & 67453 \\
\hline & 4 & 4 & 22.4 & 99.6925 & 1.7494 & 67531 \\
\hline
\end{tabular}

Table 5

Summary of the optimal solution for numerical example 2

\begin{tabular}{llllccc}
\hline$\beta$ & $\mathrm{L}$ & $\mathrm{C}(\mathrm{L})$ & $\mathrm{m}$ & $\mathrm{Q}$ & $\mathrm{k}$ & $\mathrm{PTC}_{\mathrm{sc}}^{\mathrm{M}}(\mathrm{Q}, \mathrm{k}, \mathrm{L}, \mathrm{m})$ \\
\hline 0 & 3 & 57.4 & 4 & 98.8177 & 3.8482 & 78112 \\
0.25 & 3 & 57.4 & 4 & 99.0021 & 3.4431 & 76176 \\
0.50 & 3 & 57.4 & 4 & 99.1866 & 2.9853 & 74001 \\
0.75 & 4 & 22.4 & 3 & 98.6252 & 2.4558 & 71189 \\
1 & 4 & 22.4 & 3 & 98.8382 & 1.7587 & 67453 \\
\hline
\end{tabular}


From the Tables 3 and Table 5, it is seen that as the value of the backorder ratio $\beta$ increases, integrated total cost and safety factor decrease simultaneously, while order quantity increases slightly. On comparing Table 3 and Table 5, and from Fig. 1 we can easily seen that integrated supply chain cost in normal distribution case is lesser than that of minimax distribution case corresponding to particular value of backorder ratio $\beta$. It also observe that integrated supply chain costhas minimum value when $\beta$ $=1$ (complete backorder case) and maximum value when $\beta=0$ (complete lost sales case) in both the cases.

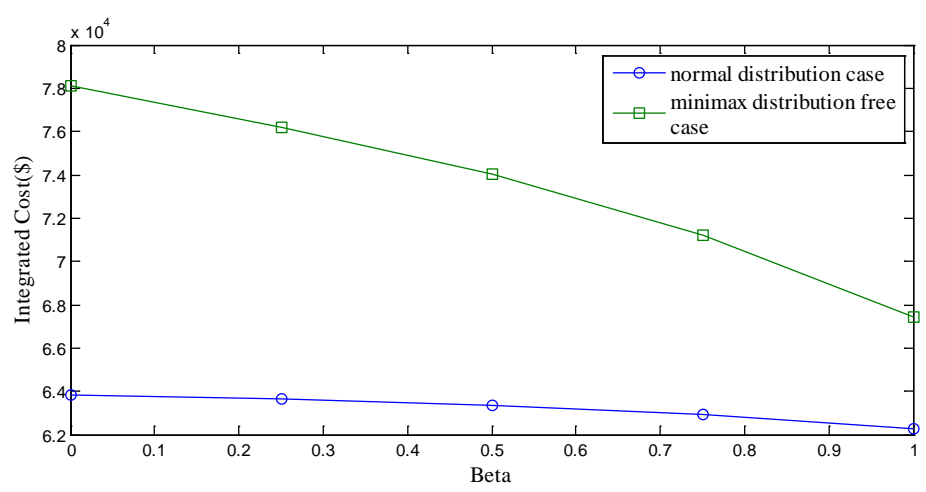

Fig. 1. Integrated cost under normal distribution case and minimax distribution free case with different $\beta$

\section{Sensitivity Analysis}

We now study the effects of changes in the model parameters $\mathrm{A}, \mathrm{D}, \sigma$, and $\theta$ on the optimal order quantity, safety factor and optimal integrated total cost in the above examples for $\beta=0.75$. The sensitivity analysis is performed by changing values of parameter A and D by $-50 \%,-25 \%,+25 \%$ and $+50 \%$ and suitable values of $\sigma$ and $\theta$ by taking one parameter at a time while keeping remaining unchanged. The results are presented in Table 6 (also see Fig. 2) and 7 (also see Fig. 3) for numerical examples 1 and 2 respectively. We get following observations:

1. Table 6 and Fig 2 illustrate following results:

I. As ordering cost A decreases, order quantity $\mathrm{Q}$ increases while safety factor $\mathrm{k}$ and integrated cost decrease simultaneously.

II. As demand rate $\mathrm{D}$ decreases, order quantity $\mathrm{Q}$ increases while safety factor $\mathrm{k}$ and integrated cost decrease simultaneously.

III. As $\sigma$ increases, order quantity Q decreases and integrated cost increase simultaneously while safety factor $\mathrm{k}$ remains unchanged.

IV. As interest rate $\theta$ increases, safety factor $\mathrm{k}$ increases while order quantity $\mathrm{Q}$ and integrated cost decrease simultaneously.

2. Table 7 and Fig 3 illustrate following results:

I. As ordering cost A decreases, order quantity $\mathrm{Q}$ increases while safety factor $\mathrm{k}$ and integrated cost decrease simultaneously.

II. As demand rate $\mathrm{D}$ decreases, order quantity $\mathrm{Q}$ increases while safety factor $\mathrm{k}$ and integrated cost decrease simultaneously.

III. As $\sigma$ increases, order quantity $\mathrm{Q}$ decreases while safety factor $\mathrm{k}$ and integrated cost increase simultaneously.

IV. As interest rate $\theta$ increases, safety factor $\mathrm{k}$ increases while order quantity $\mathrm{Q}$ and integrated cost decrease simultaneously. 
Table 6

Sensitivity analysis for numerical example 1

\begin{tabular}{|c|c|c|c|c|}
\hline Parameters & $\begin{array}{l}\text { Change in value of } \\
\text { parameter }\end{array}$ & $\begin{array}{l}\text { Change in value } \\
\text { Q }\end{array}$ & $\mathrm{k}$ & $\mathrm{PTC}_{\mathrm{sc}}(\mathrm{Q}, \mathrm{k}, \mathrm{L}, \mathrm{m})$ \\
\hline \multirow{4}{*}{$A=$} & 300 & 98.6209 & 1.788 & 69098 \\
\hline & 250 & 98.8709 & 1.786 & 66048 \\
\hline & 150 & 99.3709 & 1.783 & 59889 \\
\hline & 100 & 99.6209 & 1.782 & 56825 \\
\hline \multirow{4}{*}{$D=$} & 900 & 98.4237 & 1.965 & 79295 \\
\hline & 750 & 98.7025 & 1.886 & 71126 \\
\hline & 450 & 99.8193 & 1.650 & 54762 \\
\hline & 300 & 101.2194 & 1.443 & 46616 \\
\hline \multirow{4}{*}{$\sigma=$} & 14 & 99.1197 & 1.785 & 69074 \\
\hline & 21 & 99.1185 & 1.785 & 75194 \\
\hline & 28 & 99.1172 & 1.785 & 81315 \\
\hline & 35 & 99.1160 & 1.785 & 87436 \\
\hline \multirow{4}{*}{$\theta=$} & 0.3 & 97.3990 & 1.800 & 21503 \\
\hline & 0.5 & 95.7394 & 1.815 & 13217 \\
\hline & 0.7 & 94.1589 & 1.829 & 9675 \\
\hline & 0.9 & 92.6738 & 1.842 & 7708 \\
\hline
\end{tabular}

Table 7

Sensitivity analysis for numerical example 2

\begin{tabular}{|c|c|c|c|c|}
\hline Parameters & $\begin{array}{l}\text { Change in value of } \\
\text { parameter }\end{array}$ & $\begin{array}{l}\text { Change in value } \\
\text { Q }\end{array}$ & $\mathrm{k}$ & $\mathrm{PTC}_{\mathrm{sc}}^{\mathrm{M}}(\mathrm{Q}, \mathrm{k}, \mathrm{L}, \mathrm{m})$ \\
\hline \multirow{4}{*}{$A=$} & 300 & 98.0168 & 2.4642 & 77715 \\
\hline & 250 & 98.2668 & 2.4607 & 74571 \\
\hline & 150 & 98.7668 & 2.4538 & 68329 \\
\hline & 100 & 99.0168 & 2.4504 & 65233 \\
\hline \multirow{4}{*}{$D=$} & 900 & 97.8195 & 3.0719 & 91437 \\
\hline & 750 & 98.0983 & 2.7816 & 81496 \\
\hline & 450 & 99.2151 & 2.0835 & 61250 \\
\hline & 300 & 100.6152 & 1.6275 & 50908 \\
\hline \multirow{4}{*}{$\sigma=$} & 14 & 98.0864 & 2.4632 & 83949 \\
\hline & 21 & 97.6560 & 2.4692 & 96513 \\
\hline & 28 & 97.2256 & 2.4752 & 109130 \\
\hline & 35 & 96.7952 & 2.4812 & 121820 \\
\hline \multirow{4}{*}{$\theta=$} & 0.3 & 95.5865 & 2.5204 & 24505 \\
\hline & 0.5 & 92.7186 & 2.5838 & 15134 \\
\hline & 0.7 & 89.9297 & 2.6472 & 11130 \\
\hline & 0.9 & 87.2363 & 2.7104 & 8914 \\
\hline
\end{tabular}
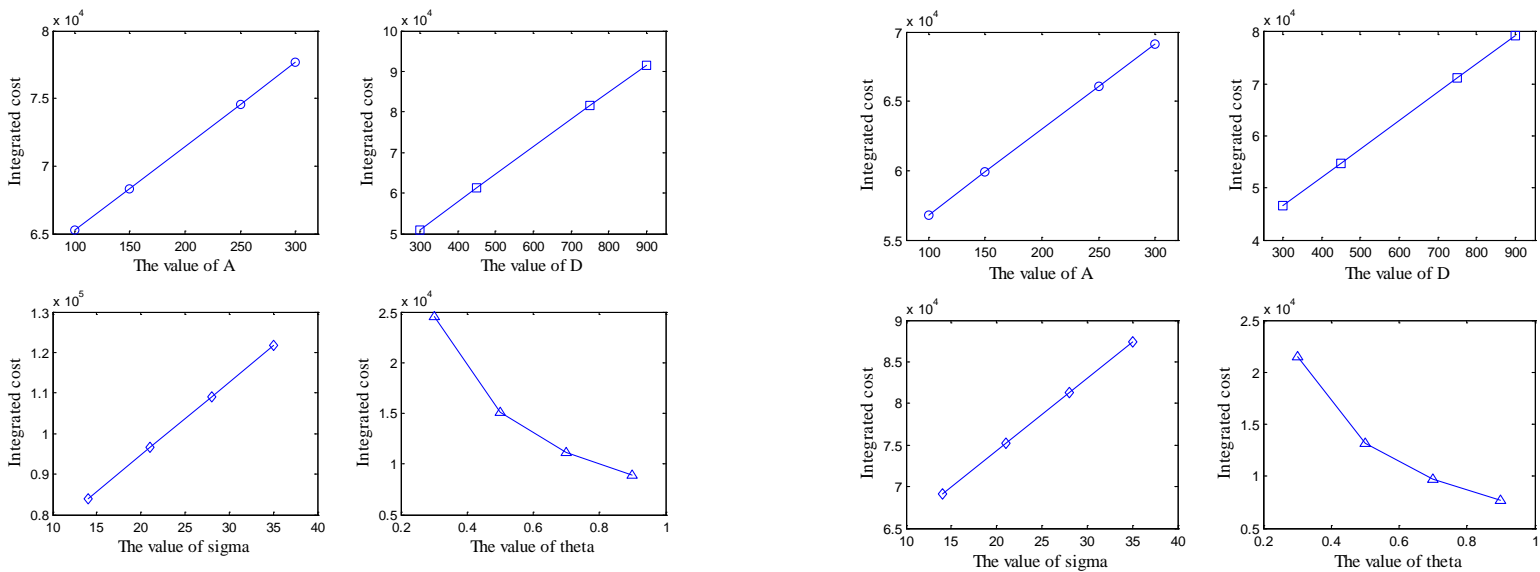

Fig. 2. Graphical representation of sensitivity Fig. 3. Graphical representation of sensitivity analysis for numerical example 1 analysis for numerical example 2 


\section{Conclusions}

In this study, we consider two single-vendor single-buyer integrated supply chain inventory models. Previous works on this problem mostly ignored inflation and time value of money. However, in the present day global scenario due to fluctuating inflation rates, financial situations of many developing countries have been changed very frequently. The effect of time value of money is not considered explicitly in analyzing inventory modeling, although time value of money would influence the cost and price components to a significant degree. Therefore, ignoring the effects of time value of money and inflation might yield misleading results. Here, we assume that demand is stochastic and the lead time is controllable. This article considers the inflation and time value of money of a continuous review inventory model with a mixture of backorders and lost sales, where lead time demand has a normal distribution. Then, we relax the assumption about the form of the distribution function of lead time demand by applying the minimax distribution free procedure to solve the problem. We seek to minimize the joint total expected cost by simultaneously optimizing ordering quantity, safety factor, lead time and the number of lots delivered from vendor to buyer. The results of the numerical examples validate significance of our models. In future research on this problem, it would be interesting to deal with a mixed inventory model with a service level constraint model. Another possible extension of this work may be conducted by considering the ordering cost reduction. The problem under consideration may also be studied to consider a three level supply chain along with coordination mechanisms that effectively enhance supply chain performance.

\section{References}

Balkhi, Z. T. (2004). An optimal solution of a general lot size inventory model with deteriorated and imperfect products, taking into account inflation and time value of money. International Journal of Systems Science, 35(2), 87-96.

Bierman, H., \& Thomas, J. (1977). Inventory decisions under inflationary conditions. Decision Sciences, 8(1), 151-155.

Buzacott, J.A. (1975). Economic order quantities with inflation. Operational Research Quarterly, 26(3), 553-558.

Chern, M.S., Yang, H.L., Teng, J.T., \& Papachristos, S. (2008). Partial backlogging inventory models for deteriorating items with fluctuating demand under inflation. European Journal of Operational Research 191(1), 125-139.

Gallego, G., \& Moon, I. (1993). The distribution free newsboy problem: review and extensions. Journal of the Operational Research Society, 44(8), 825-834.

Horowitz, I. (2000). EOQ and inflation uncertainty. International Journal of Production Economics, 65(2), 217-224.

Jindal, Prashant, \& Solanki, Anjana. (2014). Minimax distribution-free procedure for integrated inventory model with backorder price discount and controllable lead time. International Journal of Systems Science: Operations \& Logistics, 1(3), 131-141.

Lo S.T., Wee H.M., \& Huang W.C. (2007). An integrated production-inventory model with imperfect production processes and Weibull distribution deterioration under inflation. International Journal of Production Economics, 106(1), 248-260.

Mirzazadeh, A. (2011). A Comparison of the Mathematical Modeling Methods in the Inventory Systems under Uncertain Inflationary Conditions. International Journal of Engineering Science and Technology, 3, 6131-6142.

Mirzazadeh, A. (2013). Inventory management under stochastic conditions with multiple objectives. Artificial Intelligence Research, 2(3), p16. 
Misra, R.B. (1975). A study of inflationary effects on inventory systems. Logistic Spectrum, 9(3), 260268.

Misra, R.B. (1979). A note on optimal inventory management under inflation. Naval Research Logistics Quarterly, 26 (1), 161-165.

Moon, I., \& Yun, W. (1993), A note on evaluating investments inventory systems: A net present value framework. The Engineering Economist, 39(1) 93-99.

Ray, J., \& Chaudhuri, K. S. (1997). An EOQ model with stock-dependent demand, shortage, inflation and time discounting. International Journal of Production Economics, 53(2), 171-180.

Sarker, B. R., \& Pan, H. (1994). Effects of inflation and the time value of money on order quantity and allowable shortage. International Journal of Production Economics, 34(1), 65-72.

Shah, N. H., \& Shukla, K. T. (2010). Deteriorating inventory model in demand declining market under inflation when supplier credits linked to order quantity.Investigación Operacional, 31(2), 95-108.

Uthayakumar R., \& Geetha K. V. (2009). Replenishment policy for single item inventory model with money inflation. OPSEARCH, 46(3), 345-357.

Wee, H. M., \& Law, S. T. (1999). Economic production lot size for deteriorating items taking account of the time-value of money. Computers \& Operations Research, 26(6), 545-558.

Wee, H. M., \& Law, S. T. (2001). Replenishment and pricing policy for deteriorating items taking into account the time-value of money. International Journal of Production Economics, 71(1), 213-220.

Yang, G., Ronald, R. J., \& Chu, P. (2005). Inventory models with variable lead time and present value. European Journal of Operational Research, 164(2), 358-366.

\section{Appendix A}

\section{Proof of convexity of $\mathrm{PTC}_{\mathrm{sc}}(\mathrm{Q}, \mathrm{k}, \mathrm{L}, \mathrm{m})$ for normal distribution case}

To prove the convexity of $\mathrm{PTC}_{\mathrm{sc}}(\mathrm{Q}, \mathrm{k}, \mathrm{L}, \mathrm{m})$ for fixed $\mathrm{m}$ and $L \in\left[L_{i}, L_{i-1}\right]$, taking the Hessian matrix $\mathrm{H}$ as follows

$$
\left[\begin{array}{ll}
\frac{\partial^{2} \mathrm{PTC}_{\mathrm{sc}}(\mathrm{Q}, \mathrm{k}, \mathrm{L}, \mathrm{m})}{\partial Q^{2}} & \frac{\partial^{2} \mathrm{PTC}_{\mathrm{sc}}(\mathrm{Q}, \mathrm{k}, \mathrm{L}, \mathrm{m})}{\partial Q \partial k} \\
\frac{\partial^{2} \mathrm{PTC}_{\mathrm{sc}}(\mathrm{Q}, \mathrm{k}, \mathrm{L}, \mathrm{m})}{\partial k \partial Q} & \frac{\partial^{2} \mathrm{PTC}_{\mathrm{sc}}(\mathrm{Q}, \mathrm{k}, \mathrm{L}, \mathrm{m})}{\partial k^{2}}
\end{array}\right]
$$

Where

$$
\begin{aligned}
& \frac{\partial^{2} \mathrm{PTC}_{\mathrm{sc}}(\mathrm{Q}, \mathrm{k}, \mathrm{L}, \mathrm{m})}{\partial Q^{2}}=\{A+C(L)+\bar{\pi} \sigma \sqrt{L} \psi(k)\} \frac{\theta^{2}\left(1+e^{-\frac{\theta Q}{D}}\right) e^{-\frac{\theta Q}{D}}}{D^{2}\left(1-e^{-\frac{\theta Q}{D}}\right)^{3}}+\frac{S m^{2} \theta^{2}\left(1+e^{-\frac{m \theta Q}{D}}\right) e^{-\frac{m \theta Q}{D}}}{D^{2}\left(1-e^{-\frac{m \theta Q}{D}}\right)^{3}}+ \\
& \frac{h_{b} e^{-\frac{\theta Q}{D}}}{D\left(1-e^{-\frac{\theta Q}{D}}\right)^{3}}\left\{\left(2+\frac{\theta Q}{D}\right) e^{-\frac{\theta Q}{D}}-2+\frac{\theta Q}{D}\right\}
\end{aligned}
$$$$
\frac{\partial^{2} \mathrm{PTC}_{\mathrm{sc}}(\mathrm{Q}, \mathrm{k}, \mathrm{L}, \mathrm{m})}{\partial k^{2}}=\left\{\frac{\bar{\pi} \sigma \sqrt{L}}{\left(1-e^{-\frac{\theta Q}{D}}\right)}+(1-\beta) \frac{\sigma \sqrt{L} h_{b}}{\theta}\right\} \phi(k)
$$$$
\frac{\partial^{2} \mathrm{PTC}_{\mathrm{sc}}(\mathrm{Q}, \mathrm{k}, \mathrm{L}, \mathrm{m})}{\partial Q \partial k}=\frac{\bar{\pi} \theta \sigma \sqrt{\mathrm{L}} e^{-\frac{\theta Q}{D}}}{D\left(1-e^{-\frac{\theta Q}{D}}\right)^{2}}[1-\Phi(k)]
$$

Then the first principal minor of $\mathrm{H}$ is 
$\left|H_{11}\right|=\frac{\partial^{2} \mathrm{PTC}_{\mathrm{sc}}(\mathrm{Q}, \mathrm{k}, \mathrm{L}, \mathrm{m})}{\partial Q^{2}}=\{A+C(L)+\bar{\pi} \sigma \sqrt{L} \psi(k)\} \frac{\theta^{2}\left(1+e^{-\frac{\theta Q}{D}}\right) e^{-\frac{\theta Q}{D}}}{D^{2}\left(1-e^{-\frac{\theta Q}{D}}\right)^{3}}+\frac{S m^{2} \theta^{2}\left(1+e^{-\frac{m \theta Q}{D}}\right) e^{-\frac{m \theta Q}{D}}}{D^{2}\left(1-e^{-\frac{m \theta Q}{D}}\right)^{3}}+$ $\frac{h_{b} e^{-\frac{\theta Q}{D}}}{D\left(1-e^{-\frac{\theta Q}{D}}\right)^{3}}\left\{\left(2+\frac{\theta Q}{D}\right) e^{-\frac{\theta Q}{D}}-2+\frac{\theta Q}{D}\right\}>0$.

Second principal minor of $\mathrm{H}$ is

$\left|H_{22}\right|=\frac{\partial^{2} \mathrm{PTC}_{\mathrm{sc}}(\mathrm{Q}, \mathrm{k}, \mathrm{L}, \mathrm{m})}{\partial Q^{2}} \frac{\partial^{2} \mathrm{PTC}_{\mathrm{sc}}(\mathrm{Q}, \mathrm{k}, \mathrm{L}, \mathrm{m})}{\partial k^{2}}-\frac{\partial^{2} \mathrm{PTC}_{\mathrm{sc}}(\mathrm{Q}, \mathrm{k}, \mathrm{L}, \mathrm{m})}{\partial Q \partial k} \frac{\partial^{2} \mathrm{PTC}_{\mathrm{sc}}(\mathrm{Q}, \mathrm{k}, \mathrm{L}, \mathrm{m})}{\partial k \partial Q}$

$=\left[\{A+C(L)+\bar{\pi} \sigma \sqrt{L} \psi(k)\} \frac{\theta^{2}\left(1+e^{-\frac{\theta Q}{D}}\right) e^{-\frac{\theta Q}{D}}}{D^{2}\left(1-e^{-\frac{\theta Q}{D}}\right)^{3}}+\frac{S m^{2} \theta^{2}\left(1+e^{-\frac{m \theta Q}{D}}\right) e^{-\frac{m \theta Q}{D}}}{D^{2}\left(1-e^{-\frac{m \theta Q}{D}}\right)^{3}}+\frac{h_{b} e^{-\frac{\theta Q}{D}}}{D\left(1-e^{-\frac{\theta Q}{D}}\right)^{3}}\{(2+\right.$

$\left.\left.\left.\frac{\theta Q}{D}\right) e^{-\frac{\theta Q}{D}}-2+\frac{\theta Q}{D}\right\}\right]\left\{\frac{\bar{\pi} \sigma \sqrt{L}}{\left(1-e^{-\frac{\theta Q}{D}}\right)}+(1-\beta) \frac{\sigma \sqrt{L} h_{b}}{\theta}\right\} \phi(k)-\left[\frac{\bar{\pi} \theta \sigma \sqrt{L} e^{-\frac{\theta Q}{D}}}{D\left(1-e^{-\frac{\theta Q}{D}}\right)^{2}}[1-\Phi(k)]\right]^{2}$

$>\left[\frac{\bar{\pi} \theta \sigma \sqrt{L}}{D\left(1-e^{-\frac{\theta Q}{D}}\right)^{2}}\right]^{2}\left(1+e^{-\frac{\theta Q}{D}}\right) e^{-\frac{\theta Q}{D}} \phi(k) \psi(k)-\left[\frac{\bar{\pi} \theta \sigma \sqrt{L} e^{-\frac{\theta Q}{D}}}{D\left(1-e^{-\frac{\theta Q}{D}}\right)^{2}}[1-\Phi(k)]\right]^{2}$

$>\left[\frac{\bar{\pi} \theta \sigma \sqrt{L}}{D\left(1-e^{-\frac{\theta Q}{D}}\right)^{2}}\right]^{2}\left(1+e^{-\frac{\theta Q}{D}}\right) e^{-\frac{\theta Q}{D} \frac{1}{2}}[1-\Phi(k)]^{2}-\left[\frac{\bar{\pi} \theta \sigma \sqrt{L} e^{-\frac{\theta Q}{D}}}{D\left(1-e^{-\frac{\theta Q}{D}}\right)^{2}}[1-\Phi(k)]\right]^{2}$

$=\left[\frac{\bar{\pi} \theta \sigma \sqrt{L}[1-\Phi(k)]}{D\left(1-e^{-\frac{\theta Q}{D}}\right)^{2}}\right]^{2} \frac{e^{-\frac{\theta Q}{D}}}{2}\left(1-e^{-\frac{\theta Q}{D}}\right)>0 \quad \because 2 \phi(k) \psi(k)>[1-\Phi(k)]^{2}$

Since, both principal minors are positive, therefore hessian matrix $\mathrm{H}$ is positive definite.

\section{Appendix B}

\section{Proof of convexity of $\operatorname{PTC}_{s c}^{M}(Q, k, L, m)$ for minimax distribution free case}

To prove the convexity of $\operatorname{PTC}_{\mathrm{sc}}^{\mathrm{M}}(\mathrm{Q}, \mathrm{k}, \mathrm{L}, \mathrm{m})$ for fixed $\mathrm{m}$ and $L \in\left[L_{i}, L_{i-1}\right]$, taking the Hessian matrix $H^{M}$ as follows

$\left[\begin{array}{ll}\frac{\partial^{2} \mathrm{PTC}_{\mathrm{sc}}^{\mathrm{M}}(\mathrm{Q}, \mathrm{k}, \mathrm{L}, \mathrm{m})}{\partial Q^{2}} & \frac{\partial^{2} \mathrm{PTC}_{\mathrm{sc}}^{\mathrm{M}}(\mathrm{Q}, \mathrm{k}, \mathrm{L}, \mathrm{m})}{\partial Q \partial k} \\ \frac{\partial^{2} \mathrm{PTC}_{\mathrm{sc}}^{\mathrm{M}}(\mathrm{Q}, \mathrm{k}, \mathrm{L}, \mathrm{m})}{\partial k \partial Q} & \frac{\partial^{2} \mathrm{PTC}_{\mathrm{sc}}^{\mathrm{M}}(\mathrm{Q}, \mathrm{k}, \mathrm{L}, \mathrm{m})}{\partial k^{2}}\end{array}\right]$

Where

$\frac{\partial^{2} \mathrm{PTC}_{\mathrm{SC}}^{\mathrm{M}}(\mathrm{Q}, \mathrm{k}, \mathrm{L}, \mathrm{m})}{\partial Q^{2}}=\left\{A+C(L)+\frac{\bar{\pi}}{2} \sigma \sqrt{L}\left(\sqrt{1+k^{2}}-k\right)\right\} \frac{\theta^{2}\left(1+e^{-\frac{\theta Q}{D}}\right) e^{-\frac{\theta Q}{D}}}{D^{2}\left(1-e^{-\frac{\theta Q}{D}}\right)^{3}}+\frac{S^{2} \theta^{2}\left(1+e^{-\frac{m \theta Q}{D}}\right) e^{-\frac{m \theta Q}{D}}}{D^{2}\left(1-e^{-\frac{m \theta Q}{D}}\right)^{3}}+$

$\frac{h_{b} e^{-\frac{\theta Q}{D}}}{D\left(1-e^{-\frac{\theta Q}{D}}\right)^{3}}\left\{\left(2+\frac{\theta Q}{D}\right) e^{-\frac{\theta Q}{D}}-2+\frac{\theta Q}{D}\right\}$ 
$\frac{\partial^{2} \operatorname{PTCC}_{\mathrm{Sc}}^{\mathrm{M}}(\mathrm{Q}, \mathrm{k}, \mathrm{L}, \mathrm{m})}{\partial k^{2}}=\left\{\frac{\bar{\pi} \theta}{\left(1-e^{-\frac{\theta Q}{D}}\right)}+(1-\beta) h_{b}\right\} \frac{\sigma \sqrt{L}}{2 \theta\left(1+k^{2}\right)^{3 / 2}}$

$\frac{\partial^{2} \operatorname{PTC}_{\mathrm{sc}}^{\mathrm{M}}(\mathrm{Q}, \mathrm{k}, \mathrm{L}, \mathrm{m})}{\partial Q \partial \alpha}=\frac{\bar{\pi} \theta \sigma \sqrt{\mathrm{L}} e^{-\frac{\theta Q}{D}}}{2 D\left(1-e^{-\frac{\theta Q}{D}}\right)^{2}}\left[1-\frac{k}{\sqrt{1+k^{2}}}\right]$

Then the first principal minor of $H^{M}$ is

$\left|H_{11}^{M}\right|=\frac{\partial^{2} \mathrm{PTC}_{\mathrm{Sc}}^{\mathrm{M}}(\mathrm{Q}, \mathrm{k}, \mathrm{L}, \mathrm{m})}{\partial Q^{2}}=\left\{A+C(L)+\frac{\bar{\pi}}{2} \sigma \sqrt{L}\left(\sqrt{1+k^{2}}-k\right)\right\} \frac{\theta^{2}\left(1+e^{-\frac{\theta Q}{D}}\right) e^{-\frac{\theta Q}{D}}}{D^{2}\left(1-e^{-\frac{\theta Q}{D}}\right)^{3}}$

$+\frac{S m^{2} \theta^{2}\left(1+e^{-\frac{m \theta Q}{D}}\right) e^{-\frac{m \theta Q}{D}}}{D^{2}\left(1-e^{-\frac{m \theta Q}{D}}\right)^{3}}+\frac{h_{b} e^{-\frac{\theta Q}{D}}}{D\left(1-e^{-\frac{\theta Q}{D}}\right)^{3}}\left\{\left(2+\frac{\theta Q}{D}\right) e^{-\frac{\theta Q}{D}}-2+\frac{\theta Q}{D}\right\}>0$.

Second principal minor of $H^{M}$ is

$\left|H_{22}^{M}\right|=\frac{\partial^{2} \mathrm{PTC} c_{s c}^{M}(Q, k, L, m)}{\partial Q^{2}} \frac{\partial^{2} \mathrm{PTC}_{s c}^{\mathrm{M}}(\mathrm{Q}, \mathrm{k}, \mathrm{L}, \mathrm{m})}{\partial k^{2}}-\frac{\partial^{2} \mathrm{PTC}_{\mathrm{sc}}^{\mathrm{M}}(\mathrm{Q}, \mathrm{k}, \mathrm{L}, \mathrm{m})}{\partial Q \partial k} \frac{\partial^{2} \mathrm{PTC}_{\mathrm{sc}}^{\mathrm{M}}(\mathrm{Q}, \mathrm{k}, \mathrm{L}, \mathrm{m})}{\partial k \partial Q}$

$=\left[\left\{A+C(L)+\frac{\bar{\pi}}{2} \sigma \sqrt{L}\left(\sqrt{1+k^{2}}-k\right)\right\} \frac{\theta^{2}\left(1+e^{-\frac{\theta Q}{D}}\right) e^{-\frac{\theta Q}{D}}}{D^{2}\left(1-e^{-\frac{\theta Q}{D}}\right)^{3}}+\frac{S^{2} \theta^{2}\left(1+e^{-\frac{m \theta Q}{D}}\right) e^{-\frac{m \theta Q}{D}}}{D^{2}\left(1-e^{-\frac{m \theta Q}{D}}\right)^{3}}\right.$

$\left.+\frac{h_{b} e^{-\frac{\theta Q}{D}}}{D\left(1-e^{-\frac{\theta Q}{D}}\right)^{3}}\left\{\left(2+\frac{\theta Q}{D}\right) e^{-\frac{\theta Q}{D}}-2+\frac{\theta Q}{D}\right\}\right]\left\{\frac{\bar{\pi} \theta}{\left(1-e^{-\frac{\theta Q}{D}}\right)}+(1-\beta) h_{b}\right\} \frac{\sigma \sqrt{L}}{2 \theta\left(1+k^{2}\right)^{3 / 2}}$

$-\left[\frac{\bar{\pi} \theta \sigma \sqrt{L} e^{-\frac{\theta Q}{D}}}{2 D\left(1-e^{\left.-\frac{\theta Q}{D}\right)^{2}}\right.}\left[1-\frac{k}{\sqrt{1+k^{2}}}\right]\right]^{2}$

$>\left[\frac{\bar{\pi} \theta \sigma \sqrt{L}}{2 D\left(1-e^{-\frac{\theta Q}{D}}\right)^{2}}\right]^{2} \frac{\left(1+e^{-\frac{\theta Q}{D}}\right)}{\left(1+k^{2}\right)} e^{-\frac{\theta Q}{D}}\left[1-\frac{k}{\sqrt{1+k^{2}}}\right]-\left[\frac{\bar{\pi} \theta \sigma \sqrt{L} e^{-\frac{\theta Q}{D}}}{D\left(1-e^{-\frac{\theta Q}{D}}\right)^{2}}\left[1-\frac{k}{\sqrt{1+k^{2}}}\right]\right]^{2}$

$=\left[\frac{\bar{\pi} \theta \sigma \sqrt{\mathrm{L}}}{2 \mathrm{D}\left(1-\mathrm{e}^{-\frac{\theta \mathrm{Q}}{\mathrm{D}}}\right)^{2}}\right]^{2} \frac{\mathrm{e}^{-\frac{\theta \mathrm{Q}}{\mathrm{D}}}}{\left(1+\mathrm{k}^{2}\right)}\left[1-\frac{\mathrm{k}}{\sqrt{1+\mathrm{k}^{2}}}\right]\left\{\left(1+\mathrm{e}^{-\frac{\theta \mathrm{Q}}{\mathrm{D}}}\right)-\mathrm{e}^{-\frac{\theta \mathrm{Q}}{\mathrm{D}}}\left[\left(1+\mathrm{k}^{2}\right)-\mathrm{k} \sqrt{1+\mathrm{k}^{2}}\right]\right\}$

$=\left[\frac{\bar{\pi} \theta \sigma \sqrt{L}}{2 D\left(1-e^{-\frac{\theta Q}{D}}\right)^{2}}\right]^{2} \frac{e^{-\frac{\theta Q}{D}}}{\left(1+k^{2}\right)}\left[1-\frac{k}{\sqrt{1+k^{2}}}\right]\left\{1+k e^{-\frac{\theta Q}{D}}\left(\sqrt{1+k^{2}}-k\right)\right\}>0$

Since, both principal minors are positive, therefore hessian matrix $H^{M}$ is positive definite. 